\title{
Human blood monocytes, but not alveolar macrophages, reveal increased CD11b/CD18 expression and adhesion properties upon receptor-dependent activation
}

\author{
J. Lundahl*, G. Halldén*, C.M. Sköld**
}

\begin{abstract}
Human blood monocytes, but not alveolar macrophages, reveal increased CDI1b/CD18 expression and adhesion properties upon receptor-dependent activation. J. Lundahl, G. Halldén, C.M. Sköld. @eERS Journals Ltd 1996.

ABSTRACT: The $\beta_{2}$ integrin receptor CD11b/CD18 mediates adhesion to the endothelial lining as well as to extracellular matrix components. The present study was undertaken to investigate peripheral human blood monocytes (BMs) and alveolar macrophages (AMs) with respect to quantitative levels of CD11b/CD18 and adhesion properties in relation to the state of activation.

BMs and AMs were recruited from healthy subjects. Quantitative analysis of the surface expression of CD11b/CD18 by flow cytometric technique and adhesion properties to albumin-coated surfaces were performed both on resting and N-formylmethionyl-leucyl-phenylalanine (fMLP)-activated cells. Receptor independent stimuli (phorbol-12-myristate-13-acetate (PMA) and ionomycin) were used in additional experiments. Intracellular stored CD11b/CD18 was evaluated by flow cytometry and immunofluorescence microscopy.

The surface expression of CD11b/CD18 on resting BMs increased fivefold $(\mathrm{p}<0.01)$ upon fMLP activation. On resting AMs, the surface expression of CD11b/CD18 was significantly higher $(\mathrm{p}<0.01)$ compared to resting BMs but did not increase further upon activation with fMLP, PMA or ionomycin. In contrast to BMs, no evidence for an additional intracellular pool of CD11b/CD18 was found in AMs. The adherence of resting BMs did not significantly differ from the adherence of resting AMs. After fMLP activation, the adherence of BMs, but not AMs, increased significantly $(\mathrm{p}<0.05)$.

Our results indicate that in vivo differentiation of human blood monocytes into alveolar macrophages implies reduced responsiveness to fMLP in terms of CD11b/ CD18 upregulation and adhesion properties, and that the lack of upregulation of CD11b/CD18 on alveolar macrophages presumably depends on the absence of an additional intracellular pool.

Eur Respir J., 1996, 9, 1188-1194.
\end{abstract}

\author{
*Department of Clinical Immunology and \\ Transfusionmedicine, and **Department of \\ Medicine, Lung Section, Karolinska Hospital, \\ Stockholm, Sweden.
}

Correspondence: J. Lundahl

Dept. Clinical Immunology and Transfusionmedicine

Karolinska Hospital

S-17176 Stockholm

Sweden

Keywords: Adhesion

alveolar macrophages

CD11b

monocytes

Received: June 201995

Accepted after revision February 201996

This study was supported by grants from the Swedish Heart Lung Foundation, the Swedish Work Environment Found, the Swedish Medical Research Council (grant 16x-105 and 16x-08298), The Swedish Society of Medicine and Karolinska Institute.
After a period in the circulation, blood monocytes (BMs) migrate in a random order from the peripheral blood into various tissues, where they undergo final differentiation into macrophages, performing both immune and nonimmune functions [1,2]. The spectrum of processes that imply enhanced migration is broad and includes acute and chronic inflammation of disparate origin [3]. This migration procedure involves a serie of events, including a multistep interaction with the endothelial lining, diapedesis between the endothelial cells, and migration across the extracellular matrix.

BMs that migrate into the lung tissue undergo differentiation into alveolar macrophages (AMs) and remain in the tissue for several months. This population is constantly renewed by the steady influx of BMs. The AM is regarded as the main phagocyte in the alveolar space, and acts as a first-line cellular defence against inhaled microorganisms and other particles [4].

During recent years, knowledge concerning leucocyte adhesion to the endothelium has expanded. However, these studies have been focused on neutrophils, and the extent to which monocytes adapt to this concept is not established. It has, however, been suggested that the recruitment of monocytes, in conformity to neutrophils, relies primarily on the $\beta_{2}$-integrins, especially CD11a-b/CD18 [5] but, in contrast to neutrophils, also on the $\beta_{1}$-integrins [6].

During extravascular migration, monocytes attach to the extracellular matrix, which comprises different macromolecules, such as collagens, proteoglycans and glycoproteins. The migration process implies reversible adherence to these components. For this purpose, monocytes are equipped with specific cell surface receptors. The receptorligand interaction has far-reaching effects on monocyte differentiation [7], and functions such as phagocytosis [8, 9], cytotoxicity [10], arachidonic acid metabolism [11] and gene expression of inflammatory cytokines [12-15]. Based on these observations, it has been suggested that adherence is an important primary and amplifying signal for the differentiation and activation of monocytes/ macrophages. 
BMs have an intracellular pool of CD11b/CD18, which is rapidly translocated to the cell surface upon activation with different chemotactic factors [16, 17]. The intracellular location of this pool is not clearly defined but it has been suggested that monocytes, like neutrophils, have easily mobilizable secretory vesicles [18], which contain CD11b/CD18. Previous studies have revealed that monocyte adherence to extracellular matrix is substantially mediated by CD11b/CD18 [19].

The present study was undertaken to investigate the effect of in vitro differentiation of peripheral human BMs into AMs, with respect to quantitative levels of CD11b/CD18 and adhesion properties in relation to the state of activation.

\section{Material and methods}

All media used in this study contained no signs of endotoxins $\left(<0.125\right.$ European units $\left.(E U) \cdot \mathrm{mL}^{-1}\right)$ assayed using the gel-clot method. The study had the approval of the local Ethics Committee and informed consent was obtained.

\section{Preparation of blood monocytes}

Blood from the nonallergic healthy blood donors $(n=7)$ (aged 18-65 yrs) was collected into Vacutainer ${ }^{\circledR}$ tubes containing an appropriate concentration of ethylenediamine tetra-acetic acid (EDTA) (Vacutainer $4 \mathrm{~mL}$, with $50 \mu \mathrm{L}$ of $21 \%$ EDTA) (Terumo, Leuven, Belgium). The anticoagulated blood was haemolysed in $100 \mu \mathrm{L}$ portions by dilution in $2 \mathrm{~mL}$ of $4^{\circ} \mathrm{C}$ isotonic $\mathrm{NH}_{4} \mathrm{Cl}$-EDTA lysing solution $\left(154 \mathrm{mM} \mathrm{NH} \mathrm{NH}_{4} \mathrm{Cl}, 1.5 \mathrm{mM} \mathrm{KHCO}, 0.1 \mathrm{mM}\right.$ EDTA, $\mathrm{pH}$ 7.2). After incubation at $15^{\circ} \mathrm{C}$ for $5 \mathrm{~min}$, the leucocytes were centrifuged at $300 \times \mathrm{g}$ for $5 \mathrm{~min}$ at $4^{\circ} \mathrm{C}$ [20]. The leucocyte pellets were washed once at $4^{\circ} \mathrm{C}$ in $0.15 \mathrm{M}$ phosphate-buffered saline (PBS) supplemented with $0.1 \mathrm{mM}$ EDTA and $0.02 \% \mathrm{Na}$ azide (PBS-EDTA) This leucocyte isolation procedure consistently eliminated contaminating erythrocytes. Differential cell count, described as percentage and range, was as follows: monocytes $2-10 \%$, neutrophils $40-75 \%$, lymphocytes 20 $45 \%$, eosinophils $1-6 \%$, basophils $0-1 \%$. The purity of monocytes within the gate, determined as CD14+ labelled cells (phycoerythrin (PE)-conjugated anti-CD14; Coulter, Hialeah, FL, USA), was $>90 \%$

\section{Preparation of alveolar macrophages}

AMs were recruited from healthy nonsmokers $(n=7)$ and smokers ( $\mathrm{n}=7)$ (aged 21-43 yrs, median $28 \mathrm{yrs}$ ). The smokers mean cigarette consumption was $9.4 \pm 3.5$ (mean \pm SD) pack-years, and the present consumption had exceeded 10 cigarettes $\cdot$ day $^{-1}$ for the last 5 yrs. All subjects had a normal chest radiograph and were free of medication. A routine physical examination was unremarkable. Bronchoalveolar lavage (BAL) was performed by wedging the fibrebronchoscope (Olympus BF, type 4B2; Olympus Optical Co. Ltd, Japan), in a middle lobe bronchus. Five aliquots of PBS, $50 \mathrm{~mL}$ each, were then instilled, gently aspirated and collected in a siliconized bottle kept on ice, which was immediately transported to the laboratory. The
BAL fluid was strained through a layer of Dacron nets (Millipore, Cork, Ireland) and the cells were pelleted by centrifugation at $400 \times \mathrm{g}, 4^{\circ} \mathrm{C}$ for $10 \mathrm{~min}$. The total number of cells was counted in a Bürker chamber and the viability, estimated by trypan blue exclusion, was $>95 \%$. Smears for differential counts were prepared by cytocentrifugation at $500 \mathrm{rpm}$ for $3 \mathrm{~min}$ (Cytospin 2 Shandon; Southern Products Ltd, Runcorn, UK). Smears were stained with May-Grünwald Giemsa and 500 cells were counted. Alveolar cells were finally suspended in RPMI 1640 medium (Northumbria Biologicals, Crankington, UK) to a concentration of $1 \times 10^{6}$ cells $\cdot \mathrm{mL}^{-1}$. The differential cell count, described as percent and range, was as follows: alveolar macrophages $82-96 \%$, lymphocytes 1-13\%, neutrophils $1-3 \%$, eosinophils $0-3 \%$, basophils $0-0.2 \%$.

\section{Adhesion assay}

The adhesion assay was performed as described previously [21]. Briefly, culture wells, with a growth area of $3.83 \mathrm{~cm}^{2}$ (Code No. 25815-12; Corning Laboratory Science Co., New York, NY, USA), were precoated with human albumin (10 mg.mL-1, Kabi Vitrum, Stockholm, Sweden) diluted in RPMI 1640 medium for 30 min under culture conditions $\left(37^{\circ} \mathrm{C}, 5 \% \mathrm{CO}_{2} 95 \%\right.$ air atmosphere). The wells were rinsed with PBS-EDTA and air-dried. The cells (mixed leucocyte suspensions and AMs, respectively) were then added $(500 \mu \mathrm{L}$, total cell count approximately $0.5 \times 10^{6}$ ) and incubated under culture conditions $\left(37^{\circ} \mathrm{C}, 5 \% \mathrm{CO}_{2} / 95 \%\right.$ air atmosphere $)$ for $15 \mathrm{~min}$. The nonadherent cells were recovered by gently rinsing with $500 \mu \mathrm{L}$ RPMI 1640 medium at $37^{\circ} \mathrm{C}$. Finally, the percentage of adherent cells was calculated from the initial number of added cells and the number of nonadherent cells recovered. The number of cells was analysed by flow cytometry (see below).

The viability, determined by trypan blue exclusion, did not differ between the adherent and nonadherent populations, excluding the possibility that adherence is mainly related to viability.

The cell recovery rate (number of adherent cells + number of nonadherent cells/number of initial cells added) was $>95 \%$.

In blocking experiments, AMs were preincubated with either fibronectin $\left(20 \mu \mathrm{g} \cdot \mathrm{mL}^{-1}\right)$ or with the synthetic ArgGly-Asp (RGD) tripeptide $\left(0.5 \mathrm{mg} \cdot \mathrm{mL}^{-1}\right)$, (both purchased from Sigma Chemical, St. Louis, MO, USA), at $4^{\circ} \mathrm{C}$ for $15 \mathrm{~min}$. The preincubation was followed by one wash in RPMI medium before the adhesion assay.

\section{Receptor mobilization}

To obtain translocation of intracellularly stored CD11b/ CD18 to the cell surface, human BMs as well as AMs were incubated in RPMI supplemented with $5 \times 10^{-7} \mathrm{M}$ $\mathrm{N}$-formyl-methionyl-leucyl-phenylalanine (fMLP) for 15 min at $37^{\circ} \mathrm{C}$. To drive the mobilization process even further, cytochalasin $\mathrm{B}(\mathrm{CytB})$ was introduced to increase the stimulatory effect of fMLP. AMs were preincubated in RPMI medium supplemented with $10 \mu \mathrm{g} \cdot \mathrm{mL}^{-1} \mathrm{CytB}$ (Sigma Chemical Co., St. Louis, MO, USA) at $37^{\circ} \mathrm{C}$ for $3 \mathrm{~min}$ before the exposure to fMLP $\left(5 \times 10^{-7} \mathrm{M}, 15 \mathrm{~min}\right.$, $\left.37^{\circ} \mathrm{C}\right)$. 
Receptor-independent activation was performed by incubating AMs with phorbol-12-myristate-13-acetate (PMA) and ionomycin $\left(10^{-7} \mathrm{M}, 37^{\circ} \mathrm{C}, 15 \mathrm{~min}\right)$, respectively. PMA, ionomycin and AMLP were prepared from a $10^{-3} \mathrm{M}$ stock solution stored at $-70^{\circ} \mathrm{C}$, and were all purchased from Sigma Chemical Co. (St. Louis, MO, USA).

\section{Immunostaining and flow cytometry}

Since AMs from smokers have an autofluorescence [22] that significantly interferes with the detection of monoclonal antibodies, only AMs from nonsmokers were used in the immunostaining assay. In addition, we have previously demonstrated that the quantitative level of CD11b/CD18 on AMs does not differ between smokers and nonsmokers [22]. The expression of CD11b/CD18 on $\mathrm{BMs}$ and AMs was analysed by adding $5 \mu \mathrm{L}$ PE-conjugated anti-CD11b (Dako AS, Glostrup, Denmark) to cell pellets (approximately $0.5 \times 10^{6}$ cells $\cdot 100 \mu \mathrm{L}^{-1}$ ) prepared as described above. The suspensions were incubated at $4^{\circ} \mathrm{C}$ for $30 \mathrm{~min}$ and then washed twice in PBS-EDTA at $4^{\circ} \mathrm{C}$. Isotype-matched control antibodies, PE-conjugated immunoglobulin $\mathrm{G}_{1}\left(\mathrm{IgG}_{1}\right)$, were used to determine the nonspecific binding, which was subtracted from the specific binding. The nonspecific binding for BMs and AMs was measured at a mean fluorescence intensity (MFI) of $1.0 \pm 0.3$ and 3.6 \pm 1.0 units, respectively.

To enable measurements of the total detectable pool of $\mathrm{CD} 11 \mathrm{~b} / \mathrm{CD} 18$, the AMs were treated according to a previously described cell membrane permeabilization technique, the FOG-method [23-25]. The AMs were fixed by incubation with paraformaldehyde (PFA) at $20^{\circ} \mathrm{C}$ for 5 minutes followed by a wash in $4^{\circ} \mathrm{C}$ PBS-EDTA. The AMs were then incubated with the detergent n-octylbeta-D-glucopyranoside (OG) (Sigma Chemical Co., St. Louis, MO, USA) $0.74 \%$ at $20^{\circ} \mathrm{C}$ for another $6 \mathrm{~min}$, and washed once in $4^{\circ} \mathrm{C}$ PBS-EDTA. The permeabilized AMs were then incubated with $5 \mu \mathrm{L}$ monoclonal anti-CD11b and isotype-matched control antibody, respectively, at $4^{\circ} \mathrm{C}$ for $30 \mathrm{~min}$, followed by two washes in PBS-EDTA. Intracellular binding of anti-vimentin antibodies was obtained in $87.8-89.3 \%$ of the macrophage population, which confirmed that an accurate permeabilization was obtained, as described previously [23].

The cells were finally resuspended in $0.5 \mathrm{~mL}$ PBSEDTA and analysed in Epics XL-MCL (Coulter Inc., Hialeah, FL, USA). BMs and AMs were represented by well separated clusters in two-parameter scatter plot histograms with logarithmic amplification, and discrimination gates were placed around the BM and AM cluster, respectively, as described previously $[26,27]$. The instrument was calibrated daily with Standard-Brite (Coulter Inc., Hialeah, FL, USA) to ensure the same fluorescence level in each experiment. Within the respective BM and AM cluster, a minimum of 1,000 cells were accumulated for analysis.

\section{Statistics}

Results are expressed as median (range). Data were analysed using a nonparametric method (Mann-Whitney U-test) and differences were considered statistically significant at a p-level less than 0.05 .

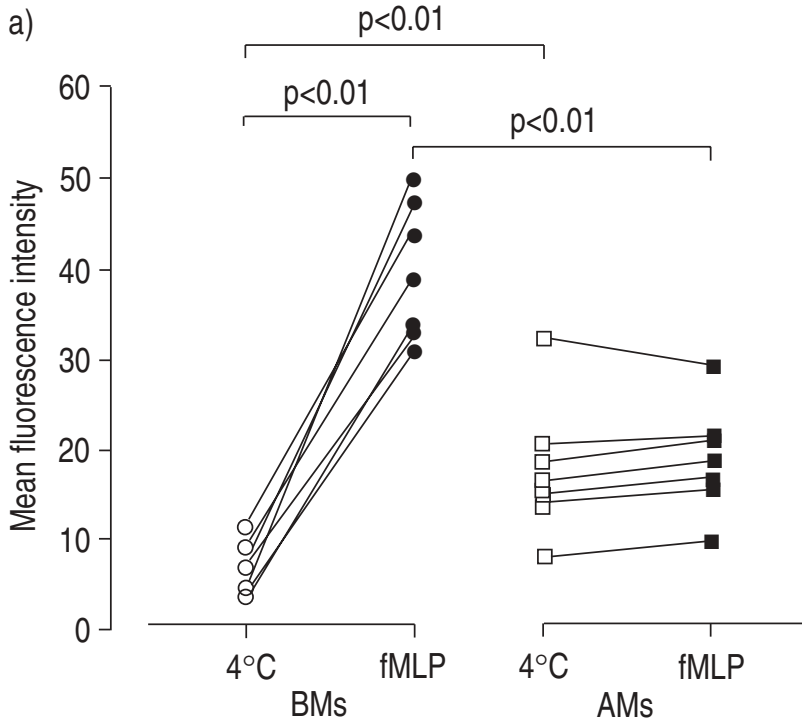

b)
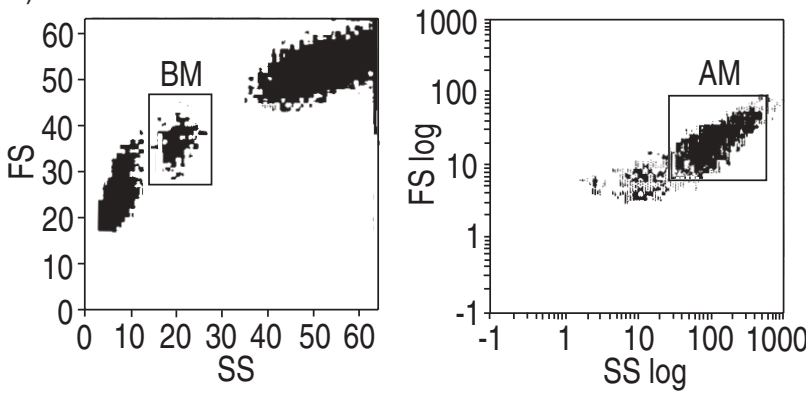

Fig. 1. - a) The surface expression of CD11b/CD18 on resting $\left(4^{\circ} \mathrm{C}\right)$ (open symbols) and stimulated (fMLP; $10^{-7} \mathrm{M} 37^{\circ} \mathrm{C}, 15 \mathrm{~min}$ ) (closed symbols) BMs (circles) and AMs (boxes). Results are presented as individual values. Statistics were performed using Mann-Whitney Utest. fMLP: N-formyl-methionyl-leucyl-phenylalaline. b) Two-parameter scatter plot histograms for peripheral blood leucocytes and cells prepared from bronchoalveolar lavage, in which blood monocytes (BMs) and alveolar macrophages (AMs), respectively, are gated. FS: forward scatter; SS: side scatter.

\section{Results}

$C D 11 \mathrm{~b} / C D 18$ expression on resting and fMLP-activated blood monocytes and alveolar macrophages

The surface expression of CD11b/CD18, described by the specific MFI units, on resting BM was 6.5 (3.1-10.9) units (fig. 1). The intracellular pool of CD11b/CD18 was rapidly translocated to the plasma membrane upon activation with the chemotactic factor fMLP $\left(10^{-7} \mathrm{M}, 37^{\circ} \mathrm{C}\right.$, $15 \mathrm{~min})$, increasing the surface expression fivefold (6.5 (3.1-10.9) vs 38.3 (31.2-49.4) units; $\mathrm{p}<0.01 ; \mathrm{n}=7)$. Receptor-independent stimuli (ionomycin and PMA, $10^{-7} \mathrm{M}$, $37^{\circ} \mathrm{C}, 15 \mathrm{~min}$ ) increased the surface expression of $\mathrm{CD} 11 \mathrm{~b} /$ CD18 on monocytes, 22.2 (16.8-23.5) and 21.7 (18.9-23.1) units, respectively. On resting AMs, the surface expression of CD11b/CD18 was significantly higher compared to resting BMs (15.3 (7.6-31.8) vs 6.5 (3.1-10.9) units; $\mathrm{p}<0.01 ; \mathrm{n}=7)$ but did not increase further upon activation with fMLP (15.3 (7.6-31.8) vs 18.1 (9.3-28.7) units; NS; $n=7)$. No further increase in CD11b/CD18 expression on AMs was obtained when cytochalasin B (a well-known inhibitor of microfilament assembly) [28] was introduced 


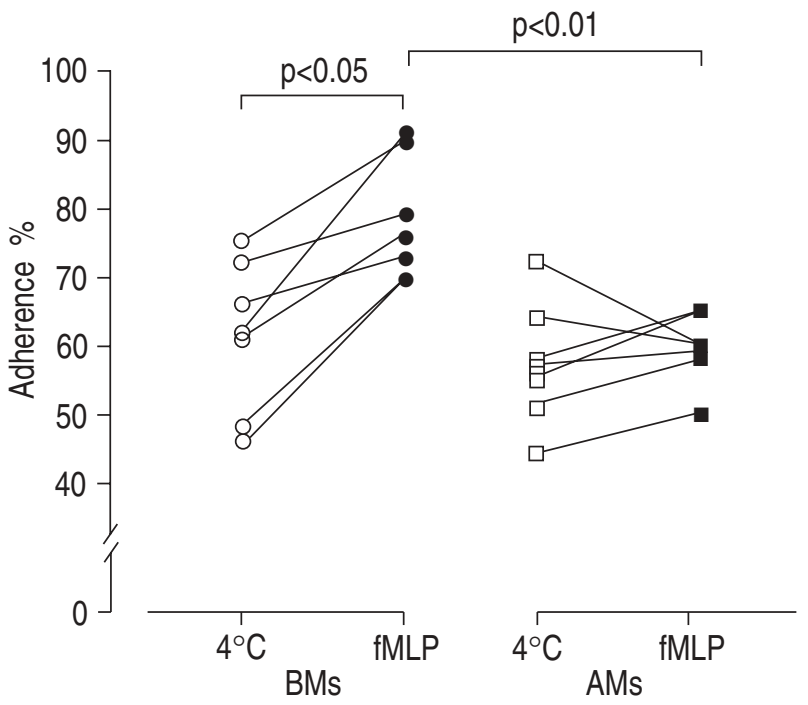

Fig. 2. - The percentage adherence of resting $\left(4^{\circ} \mathrm{C}\right)$ (open symbols) and stimulated (fMLP; $10^{-7} \mathrm{M}, 37^{\circ} \mathrm{C}, 15 \mathrm{~min}$ ) (closed symbols) BMs (circles) and AMs (boxes). Results are presented as individual values. Statistics were performed using Mann-Whitney U-test. For abbreviations see legend to figure 1 .

to increase the stimulatory effect of fMLP. In addition, receptor-independent stimuli (ionomycin and PMA, 10-7 $\mathrm{M}, 37^{\circ} \mathrm{C}, 15 \mathrm{~min}$ ) had no significant effect on the surface expression of CD11b/CD18 on AMs (data not shown).

Adherence of resting and fMLP activated blood monocytes and alveolar macrophages to albumin-coated surfaces

The adherence of resting BMs to albumin-coated surfaces was $62(46-75) \%$, which increased significantly when the chemotactic factor fMLP $\left(10^{-7} \mathrm{M}, 37^{\circ} \mathrm{C}, 15 \mathrm{~min}\right)$ was added during the incubation (62 (46-75) vs 76 (70 91) $\%$; $<0.05 ; n=7$ ) (fig. 2). The adherence of resting AMs was 57 (44-72) \%, which was unaltered after addition of fMLP (57 (44-72) vs 60 (50-65) \%; Ns; $\mathrm{n}=7$ ). The adherence of resting BMs did not significantly differ from the adherence of resting AMs (62 (46-75) vs 57 (44-72)\%; Ns; $n=7)$. However, fMLP-activated BMs adhered significantly more to albumin-coated surfaces compared to fMLPactivated AMs (76 (70-91) vs $60(50-65) \%$; $<<0.01 ; \mathrm{n}=$ 7).

In blocking experiments, neither fibronectin nor RGD peptide, significantly decreased the adhesion of AMs to albumin-coated surface (data not shown).

\section{Determination of intracellular stored CD11b/CD18 in alveolar macrophages}

Since fMLP-activated BMs expressed quantitatively more $\mathrm{CD} 11 \mathrm{~b}$ antigens on the surface as compared to AMs, the experiments were extended to include determination of an eventual intracellular stored pool of CD11b/CD18 in AMs. We were not able to detect any additional intracellular pool of CD11b/CD18 antigens in permeabilized AMs as compared to nonpermeabilized, using the FOG-method. The lack of an additional intracellular pool of CD11b/CD18 in AMs was supported by immunofluorescence microscopy using both FOG-treated and acetone-fixed $\left(99.5 \%, 20^{\circ} \mathrm{C}\right.$, $10 \mathrm{~min}$ ) AMs as sources. Fluorescence studies were performed using an incident-light ultra violet (UV) microscope (LaborluxD; Leica, Wetzlar, Germany). The fluorescence pattern in the UV microscope illustrates the predominantly intracellular location of CD11b/CD18 in resting permeabilized (FOG-treated) BMs as opposed to the AMs, in which no additional fluorescence was obtained after permeabilization (FOG treatment) (fig. 3). Comparable fluorescence patterns were obtained after acetone fixation.

\section{Discussion}

In this study, we demonstrate that differentiation of human BMs into AMs implies reduced responsiveness to fMLP in terms of CD11b/CD18 mobilization and adhesion properties, and that the lack of upregulation of CD11b/CD18 on AMs presumably depends on the absence of an additional intracellular pool.

During recent years, our knowledge concerning leucocyte trafficking has expanded and reveals that various receptor-ligand pairs act in a sequential order to mediate a proper and selective recruitment. Extravasation and adhesion of human monocytes relies primarily on the $\beta_{2}$ and $\beta_{1}$-integrins $[5,6]$, and these cells have an intracellular pool of the $\beta_{2}$-integrin CD11b/CD18, which is rapidly translocated to the cell surface upon stimulation [16, 17]. The intracellular location of this pool is not clearly defined but it has recently been suggested that monocytes, like neutrophils, have an easily mobilizable pool of CD11b/CD18 stored in secretory vesicles [18].

The recruitment of monocytes into different tissues also implies adherence to different surfaces, including collagen, fibronectin and laminin. Adherence is an important immunological step that is not only essential for the migration process but also serves as an important signal for a variety of different functions [8-15]. Adherence events can also prime the cells for augmented activity in the presence of an additional environmental stimuli [28]. An awareness of this is important, particularly in in vitro experiments, in which contaminating endotoxins can influence the results. Our experiments were carried out under accurately defined endotoxin-free conditions.

In our adhesion assay, albumin was chosen as substrate for $\mathrm{BM}$ and $\mathrm{AM}$ adhesion. The reason for using albumin is the observation that monocytes in vitro adhere and migrate on surfaces coated with apparently nonphysiological substrates, such as albumin in a CD11b-c/ CD18 dependent manner. The mechanism mediating this effect is not clear but it has been suggested that CD11b-c/ CD18 have the ability to bind denaturated protein sequences [29]. One might speculate that, during their transmigration, monocytes and neutrophils actively denaturate proteins in their environment, establishing a substrate suitable for interaction with cellular bound integrin receptors.

During the recruitment phase, the BMs are directed by different chemoattractants, such as the chemotactic peptide $\mathrm{N}$-formyl-methionine-leucine-phenylalanine lysine (fMLPL) [30], and possess functionally active receptors for this peptide [31]. On the other hand, AMs possess a reduced quantity of fMLP receptors, which is paralleled to diminished density of $\mathrm{G}_{1}$ proteins [32]. In this study, 
a) Resting nonpermeabilized BM

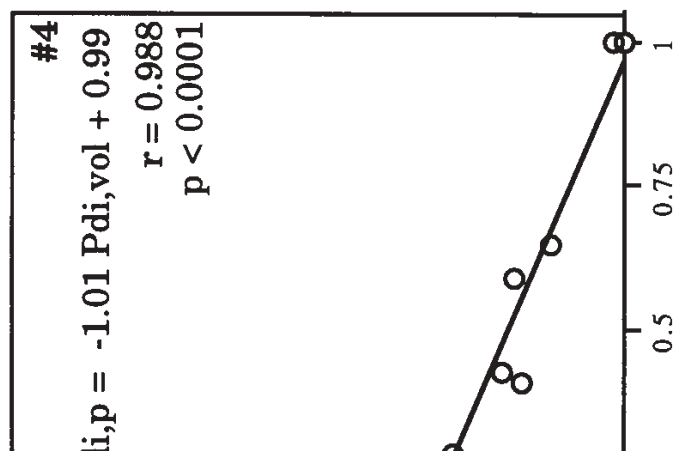

b) Resting permeabilized BM

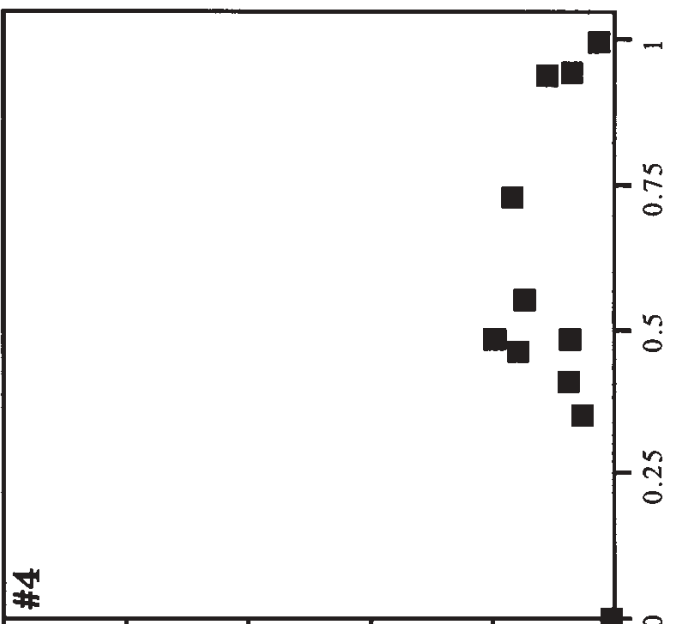

c) Resting nonpermeabilized AM

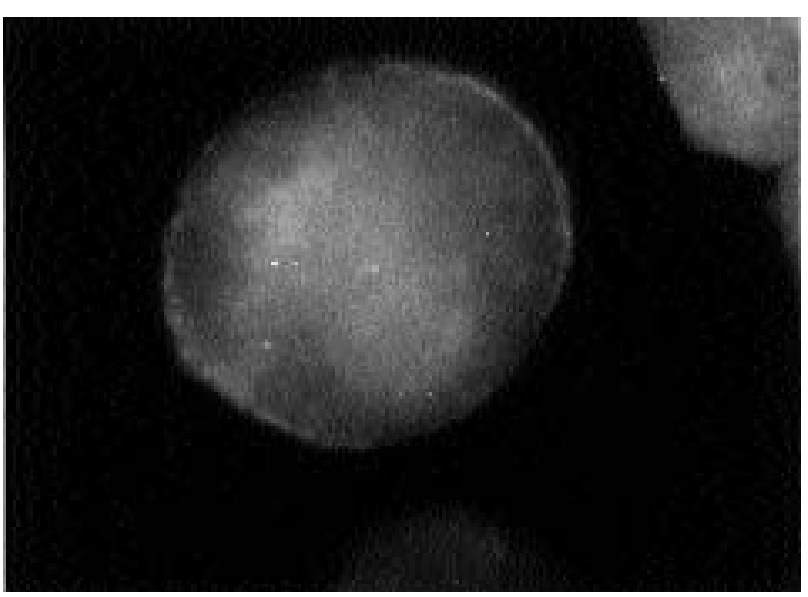

d) Resting, permeabilized AM

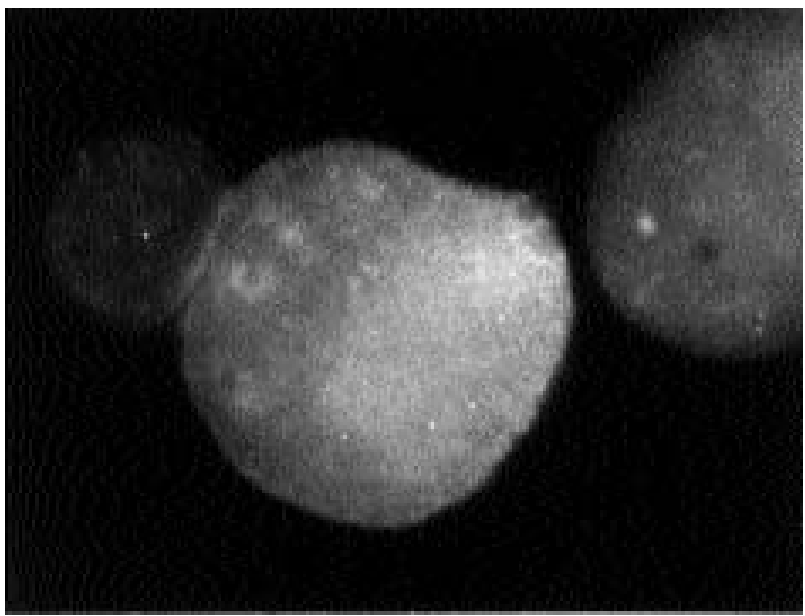

Fig. 3. - Immunofluorescence pattern of: a) resting nonpermeabilized BMs and c) AMs; as compared to b) resting permeabilized (FOG-treated) BMs; and d) resting permeabilized (FOG-treated (see "Material and methods") AMs. The fluorescence pattern illustrates the predominantly intracellular location of $\mathrm{CD} 11 \mathrm{~b}$ in resting BMs as opposed to AMs, in which no additional fluorescence was obtained after permeabilization. BMs: blood monocytes; AMs: alveolar macrophages.

we have demonstrated that the chemotactic factor fMLP in BMs induces an increased CD11b upregulation in parallel with increased adherence to albumin, which is in contrast to AMs, in which fMLP did not influence CD11/ CD18 expression or adherence. This observation is consistent with other studies showing no effect of fMLP on CD11b/CD18 expression on AMs [16]. Since AMs possess a reduced quantity of fMLP receptors, we added cytochalasin B, a well-known inhibitor of microfilament assembly, to increase the stimulatory effect of fMLP. No further increase in surface expression of CD11b/CD18 was obtained. Together, these results indicate that factors like fMLP may preferentially influence the biological properties of BMs, and to a lesser extent AMs.

To further explore the reason(s) for the absence of CD11b/ CD18 upregulation on AMs, we used a variety of different receptor-independent (PMA and ionomycin) stimuli which bypass the proximal steps of the receptordependent pathways. Since no upregulation was obtained, we evaluated the existence of an intracellular pool using two independent methods (flow cytometry and immunofluorescence microscopy). We found no evidence for an additional intracellular pool in AMs. Inaccuracies owing to insufficient permeabilization and effect on antigenicity, causing underestimation of the intracellular pool, cannot completely be excluded but are unlikely, since an accurate intracellular binding of anti-vimentin antibodies was obtained. In addition, we have previously reported that the detergent concentration used is optimal and without significant effect on antigenicity [23, 24], which further supports the view that an accurate permeabilization was attained.

The fate of CD11b/CD18 during transformation of BMs into AMs is not clear. One might speculate that the observed downregulation is a result of shedding, degradation or a combination of both. CD11b/CD18 belongs to an integrin family that lacks the site for proteolytic cleavage [33], but notwithstanding, CD11b has been found in a soluble form with retained functional capacity [34].

We have previously reported that resting AMs have a higher expression of $\mathrm{CD} 11 \mathrm{~b} / \mathrm{CD} 18$ than the corresponding BMs [26]. This may reflect the phenotypic change that occurs in vivo during the transformation of $\mathrm{BMs}$ into AMs. In this study, we have extended this observation 
including both resting and fMLP-activated BMs/AMs as well as a functional aspect, namely CD11b/CD18 dependent adhesion. We used a method that allows interpretation of data at a quantitative level with a minimum of in vitro modulation, which permits comparative studies of BMs/AMs of disparate origin [27]. Our results indicate that the level of surface bound CD11b/CD18 on resting $\mathrm{BMs}$ is below the level on corresponding $\mathrm{AMs}$ but that the surface bound CD11b/CD18 is rapidly increased due to a mobilizable intracellular pool. This pool can easily be translocated to the cell surface during different monocyte isolation and separation procedures as well as after in vitro activation. That resting BMs, as compared to AMs, are in a state of increased responsiveness towards fMLP is further supported by our finding that BMs, in contrast to AMs, increase their adherence to albumin after fMLP activation.

We found a discrepancy between the baseline expression of CD11b/CD18 and the baseline adherence in BMs and AMs. The reason(s) for this finding is not clear but may indicate that other adhesion pathways, involving $\beta_{1^{-}}$ integrins and selectins, mediate the adhesion of resting monocytes [35]. However, since the internal pool of CD11b/CD18 in monocytes is easily mobilized, we cannot exclude the possibility that the internal pool is partially mobilized due to the adhesion assay conditions. In addition, a quantitative change in CD11b/CD18 is not necessary for increased adhesive capabilities, since qualitative changes can also increase the affinity/avidity of the receptor [36].

There is currently some controversy in the literature regarding the $\mathrm{CD} 11 \mathrm{~b} / \mathrm{CD} 18$ expression on monocytes and macrophages, respectively. Several groups have reported downregulation both during in vitro and in vivo differentiation $[37,38]$ which is in contrast to a study by GESSANI et al. [28] reporting upregulation of CD11b/CD18 during culture of human monocytes into macrophages. Differences in cell preparation procedures and culture conditions may partially explain differences between monocytes and monocyte-derived macrophages. In addition, the observation that the originally intracellular localized pool of CD11b/CD18 in monocytes is easily translocated to the cell surface already during the cell preparation step renders comparative studies more difficult.

The biological significance of CD11b/CD18 for AMs is not established. It has been proposed that CD11b/CD18 on AMs are mobile and preferentially act synergistically with cytoskeleton-linked CR4 (CD11c/CD18) [39]. CD11b/ CD18 and CD11c/CD18 may satisfy different requirements for adhesion processes in the two microenvironments, the peripheral blood and the bronchoalveolar space, respectively. We were not able to block the adhesion of AMs by either fibronectin or the synthetic peptide RGD, which indicates the participation of adhesion pathways other than CD11b/CD18-mediated in the adhesion of AMs to albumin coated surfaces.

To summarize, in this study we present data that support the view that the quantitative surface level of CD11b/ CD18 on alveolar macrophages is higher compared to resting peripheral blood monocytes but that peripheral blood monocytes, as opposed to alveolar macrophages, rapidly increase their quantitative surface level due to an intracellularly localized pool of CD11b/CD18. An awareness of in vitro modulation of easily mobilizable antigens is important, particularly in studies comparing the quantitative level of these antigens on leucocyte subsets of disparate origin.

\section{Acknowledgements: The authors thank M. Hallgren for excellent and skilful technical assistance.}

\section{References}

1. Wahl SM. Acute and chronic inflammation. In: Zembala M, Asherson GL, eds. Human Monocytes. San Diego, Academic Press, 1989; pp. 361-371.

2. Stein M, Keshav S. The versatility of macrophages. Clin Exp Allergy 1992; 22: 19-27.

3. van Furth R, Diesselhoff den Dulk MMC, Mattie H. Quantitative study on the production and kinetics of mononuclear phagocytes during an acute inflammatory reaction. J Exp Med 1973; 138: 1314-1330.

4. du Bois RM. The alveolar macrophage. Thorax 1985; 40: 321-327.

5. Carlos TM, Harlan JM. Leukocyte endothelial adhesion molecules. Blood 1994; 84: 2068-2101.

6. Luscinskas FW, Kansas GS, Ding H, et al. Monocyte rolling, arrest and spreading on IL-4 activated vascular endothelium under flow is mediated via sequential action of L-selectin, $\beta_{1}$-integrins and $\beta_{2}$-integrins. J Cell Biol 1994; 125: 1417-1427.

7. Kaplan G, Gaudernack G. In vitro differentiation of human monocytes: differences in monocyte phenotypes induced by cultivation on glass or on collagen. $J$ Exp Med 1982; 156: 1101-1114.

8. Bohnsack JF, Kleinman HK, Takahashi T, O'Shea JJ, Brown EJ. Connective tissue proteins and phagocytic cell function: laminin enhances complement and Fc-mediated phagocytosis by cultured human macrophages. $J$ Exp Med 1985; 161: 912-923.

9. Newman SLK, Tucci MA. Regulation of human monocyte/macrophage function by extracellular matrix: adherence of monocytes to collagen matrices enhances phagocytosis of opsonized bacteria by activation of complement receptors and enhancement of $\mathrm{Fc}$ receptor function. $J$ Clin Invest 1990; 86: 703-714.

10. Kaplan G. In vitro differentiation of human monocytes: monocytes cultured on glass are cytotoxic to tumor cells but monocytes cultured on collagen are not. J Exp Med 1983; 157: 2061-2072.

11. Gudewicz PW, Frewin MB, Heinel LA, Minnear FL. Priming of human monocyte superoxide production and arachidonic acid metabolism by adherence to collagenand basement membrane coated surfaces. J Leukoc Biol 1994; 55: 423-429.

12. Fuhlbrigge RC, Chaplin DD, Kiely JM, Unanue ER. Regulation of interleukin-1 gene expression by adherence and lipopolysaccharide. J Immunol 1987; 138: 3799-3802.

13. Eierman DF, Johnson CE, Haskill JS. Human monocyte inflammatory mediator gene expression is selectively regulated by adherence substrates. J Immunol 1989; 142: 1970-1976.

14. Couturier C, Haeffner-Cavaillon N, Weiss L, Fischer E, Kazatchkine MD. Induction of cell-associated interleukin-1 through stimulation of the adhesion-promoting proteins LFA-1 (CD11a/CD18) and CR3 (CD11b/CD18) of human monocytes. Eur J Immunol 1990; 20: 999-1005.

15. Standiford TJ, Kunkel SL, Kasahara K, Milia MJ, Rolfe MW, Strieter RM. Interleukin-8 gene expression from 
human alveolar macrophages: the role of adherence. $A m$ J Respir Cell Mol Biol 1991; 5: 579-585.

16. Miller LJ, Bainton DF, Borregaard N, Springer TA. Stimulated mobilization of monocyte Mac-1 and p150.95 adhesion proteins from an intracellular vesicular compartment to the cell surface. J Clin Invest 1987; 80: 535-544.

17. Freyer DR, Morganroth ML, Rogers CE, Arnaout MA, Todd RF. Modulation of surface CD11/CD18 glycoproteins (Mo1, LFA-1, p150.95) by human mononuclear phagocytes. Clin Immunol Immunopathol 1988; 46: 272281.

18. Calafat J, Kuijpers TW, Janssen H, Borregaard N, Verhoeven AJ, Roos D. Evidence for small intracellular vesicles in human blood phagocytes containing cytochrome b558 and the adhesion molecule CD11b/CD18. Blood 1993; 11: 3122-3129.

19. Owen CA, Campbell EJ, Stockley RA. Monocyte adherence to fibronectin: role of CD11b/CD18 integrins and relationship to other monocyte function. J Leukoc Biol 1992; 51: 400-408.

20. Hed J, Berg O, Forslid J, Halldén G, Lärka-Raffner G. The expression of CR1 and CR3 on nonmodulated and modulated granulocytes of healthy blood donors as measured by flow cytofluorometry. Scand J Immunol 1988; 28: 339-344.

21. Sköld CM, Barck C, Lundahl J, Johansson A. Different functional and morphological characteristics in a nonadherent subpopulation of human macrophages recovered by bronchoalveolar lavage. Eur Respir J 1995; 8: 1719-1724.

22. Sköld CM, Eklund A, Halldén G, Hed J. Autofluorescence in human alveolar macrophages from smokers: relation to cell surface markers and phagocytosis. Exp Lung Res 1989; 15: 823-835.

23. Halldén G, Andersson U, Hed J, Johansson SGO. A new membrane permeabilization method for the detection of intracellular antigens by flow cytometry. J Immunol Methods 1989; 124: 103-109.

24. Lundahl J, Halldén G, Hed J, Johansson SGO. A flow cytometric method to measure the stimulated mobilization and the intracellular pool of the adhesion promoting glucoprotein Mac-1. APMIS 1991; 99: 139-146.

25. Lundahl J, Halldén G, Hed J. Differences in intracellular pool and receptor dependent mobilization of the adhesion promoting glycoprotein Mac-1 between eosinophils and neutrophils. J Leukoc Biol 1993; 53: 336-341.

26. Sköld CM, Eklund A, Halldén G, Hed J. Different cell surface and phagocytic properties in mononuclear phagocytes from blood and alveoli. APMIS 1990; 98: 415-422.
27. Lundahl J, Halldén G, Hallgren M, Sköld CM, Hed J. Altered expression of CD11b/CD18 and CD62L on human monocytes after cell preparation procedures. J Immunol Methods 1995; 180: 93-100.

28. Gessani S, Testa U, Varano B, et al. Enhanced production of LPS-induced cytokines during differentiation of human monocytes to macrophages. J Immunol 1993; 151: 3758-3766.

29. Davis GE. The Mac-1 and p150,95 $\beta_{2}$-integrins bind denaturated proteins to mediate leukocyte cell-substrate adhesion. Exp Cell Res 1992; 200: 242-252.

30. Snyderman R, Pike MC. Chemoattractant receptors on phagocytic cells. Ann Rev Immunol 1984; 2: 257-281.

31. van Epps DE, Simpson SJ, Chenoweth DE. C5a and formyl peptide receptor regulation on human monocytes. J Leukoc Biol 1992; 51: 393-399.

32. Beaty CD, Martin TR, Wilson CB. Signal transduction in human alveolar macrophages: diminished chemotactic response to fMLP correlates with a diminished density of $\mathrm{G}_{1}$ proteins and fMLP receptors. Am J Respir Cell Mol Biol 1991; 5: 87-92.

33. Arnaout MA. Structure and function of the leukocyte adhesion molecules CD11/CD18. Blood 1990; 75: 1037 1050.

34. Dana N, Fathallah DM, Arnaout MA. Expression of a soluble and functional form of the human beta -integrin $^{2}$ CD11b/CD18. Proc Natl Acad Sci USA 1991; 88: 3106-3110.

35. Carlos T, Kovach N, Schwartz B, et al. Human monocytes bind to two cytokine-induced adhesive ligands on cultured human endothelial cells: endothelial-leukocyte adhesion molecule-1 and vascular cell adhesion molecule-1. Blood 1991; 77: 2266-2275.

36. Carlos T, Harlan J. Leukocyte-endothelial adhesion molecules. Blood 1994; 84: 2068-2101.

37. Löms Ziegler-Heitbrock HW, Fingerle G, Ströbel M, et al. The novel subset of CD14+/CD16+ blood monocytes exhibits features of tissue macrophages. Eur J Immunol 1993; 23: 2053-2058.

38. Prieto J, Eklund A, Patarroyo M. Regulated expression of integrins and other adhesion molecules during differentiation of monocytes into macrophages. Cell Immunol 1994; 156: 191-211.

39. Ross GD, Reed W, Dalzell JG, Becker SE, Hogg N. Macrophage cytoskeleton association with CR3 and CR4 regulates receptor mobility and phagocytosis of iC $3 b$ opsonized erythrocytes. J Leukocyte Biol 1991; 51: 109-117. 